\title{
NUMERICAL ANALYSIS OF CONTACT PLASTIC BODIES MADE BY ALUMINIUM ALLOY WITH TAKING ACCOUNT OF MICRO-ROUGHNESS SURFACES
}

\author{
PaweŁ Sidun \\ Bialystok University of Technology, Faculty of Mechanical Engineering, Bialystok, Poland \\ e-mail: pawel.sidun.pb@gmail.com \\ JAN PIWNIK \\ COBRABID Warszawa, Research Center, Poland and \\ Road and Bridge Research Institute, Warsaw, Poland
}

\begin{abstract}
The following article describes selected aspects of numerical modeling of the process of bonding metal alloys with consideration for micro-roughness. Plastic contact between two deformable bodies is studied within a DEFROM FEM environment. The paper presents selected numerical analysis results for an aluminum alloy. The mathematical model of surface roughness has been created on the basis of the surface real profile. The dependence between the tool lathe angle and the feed has been used to build a numerical model of roughness after completion of the turning process. The article investigates the impact of wave roughness in respect to the size effect and the possibility of cold welding as well as the simplification process of real surface roughness.
\end{abstract}

Keywords: bonding process, FEM analysis, cold welding, wave roughness

\section{Introduction}

Methods of forming metals are widely used in industry increasing production rates. They are characterized by high accuracy, repeatability of dimensions and shapes as well as excellent surface quality. It is possible to apply them on the micro scale, however, it results in specific new technological problems, the so called "size effect", caused by the objects small dimensions, especially when the method employs specimens with dimensions smaller than $1 \mathrm{~mm}$. In micro-scale, the entire volume of the material is treated as its surface without distinctions into layers. This is the reason why methods used in carrying out experiments as well as those used in physical, analytical and numerical analyses should always account for scale. Piwnik and Mogielnicki (2010) investigated the influence of the scale effect during the process of micro-extrusion. The results of their numerical simulations showed that extrusion forces increase significantly with very coarse surfaces.

Literature contains numerous studies related to elastic-plastic contact between surfaces. Sun and his team (Sun et al., 2013) investigated the process of flattening sinusoidal surfaces from the perspective of the effect of plastic deformation on wear parameters. Manoylovet et al. (2013) studied elastic-plastic contact of dry surfaces to establish their wear parameters while Wang et al. (2007) examined elastic-plastic contact in the extrusion process in relation to microvillic roughness. Matsumoto et al. (2014) studied elastic-plastic contact in the extrusion process utilizing the retreat and advance pulse ram motion on a servo press. The effects of scale were also studied by Zhang et al. (2003) in respect to micro-mechanical friction during metal forming. Furthermore, literature shows an analytical approach to solving the issue of full plastic contact using statistical tools (Ma et al., 2010). Abdo and Farhgang (2005) investigated elasto-plastic 
contact of rough surfaces and compared forming methods and models with the results of their own experiments while Cai and Bhushan (2005) developed a numerical approach to modeling elastic-plastic contact of uneven surfaces investigating multi-layered elastic/plastic surfaces. Poulios and Klit (2013) also studied this kind of problem. The way they approached the issue was both innovative and very interesting since before them, situations in which both contact surfaces were elastic-plastic had not been considered.

The final item which must be included in the above-mentioned review of literature is the semi-analytical model of elastic-plastic contact. Zhang et al. (2014) presented the impact of surface roughness on the effectiveness of the elastic-plastic area of contact. Additionally, similar works dealing with modeling of elasto-plastic surface contact with boundary roughness (Brzoza and Pauk, 2007) and (Buczkowski and Kleiber, 1992) contact problems connected with a nonlinear interface compliance can also be found in literature. The article presents a new approach to modeling entirely plastic rough contact areas of two aluminum alloy deformable bodies which take into consideration the parameters of wavy roughness on the obtained values of stress, strain, and strain rate fields in micro-scale. These fields are also used to determine strain forces as well as to investigate the influence of wavy roughness on the possibility of cold welding during the bonding process.

\section{Modeling of roughness}

In the process of modeling metal forming processes, it is possible to distinguish many models of friction. The appropriate selection of a friction model mainly depends on friction conditions. An excellent comparison of friction models occurring during metal forming processes was presented by Tan (2002). On the basis of this list and the commonly accepted laws describing friction models, it is possible to distinguish two laws describing problems connected with elastic-plastic issues. The FEM environments implement these two laws as necessary dependencies describing the impact of stress and deformation caused by friction:

- Coulomb's law - describes friction in the elastic range

$$
\mu=\frac{F_{f}}{N}=\frac{\tau_{f} A}{\sigma_{n} A}=\frac{\tau_{f}}{\sigma_{n}} \Rightarrow \tau_{f}=\mu \sigma_{n}
$$

- constant shear stress law - for plastic friction

$$
\tau_{f}=f \bar{\sigma}=m \frac{\bar{\sigma}}{\sqrt{3}}=m k
$$

where: $\tau_{f}$ is the frictional stress $[\mathrm{MPa}], N-$ normal force $[\mathrm{N}], F_{f}-$ frictional force $[\mathrm{N}], A-$ contact area $\left[\mathrm{mm}^{2}\right], \mu$ - friction coefficient, $m$ - frictional shear factor $0 \leqslant m \leqslant 1, k$ - shear yield strength $[\mathrm{MPa}], \bar{\sigma}$ - effective stress $[\mathrm{MPa}], f$ - friction factor.

The simplest way to describe a micro-roughness model is through the use of Fourier series (2.3) which is also practical for the analysis of periodic signals. When it comes to numerical analyses, this method of describing roughness is the easiest and makes it possible to investigate the influence of both wavelengths and wave amplitudes, which is very useful in the analysis of the process of cold welding:

- for integer $N \geqslant 1$, the Fourier series is expressed as

$$
S_{N}=\frac{A_{0}}{2}+\sum_{i-1}^{N} A_{i} \sin \left(\frac{2 \pi i x}{T}+\varphi_{i}\right)
$$

— for $i=1, A_{0}=0, \varphi_{1}=0, T=2 \pi$, equation (2.3) takes the form

$$
S_{N}=A_{1} \sin x
$$


Equation (2.4) is used for describing the geometry of surfaces after the turning process. Figure 1 presents the dependency between surface micro-roughness after turning with the simplest form of the Fourier series equation.

(a)

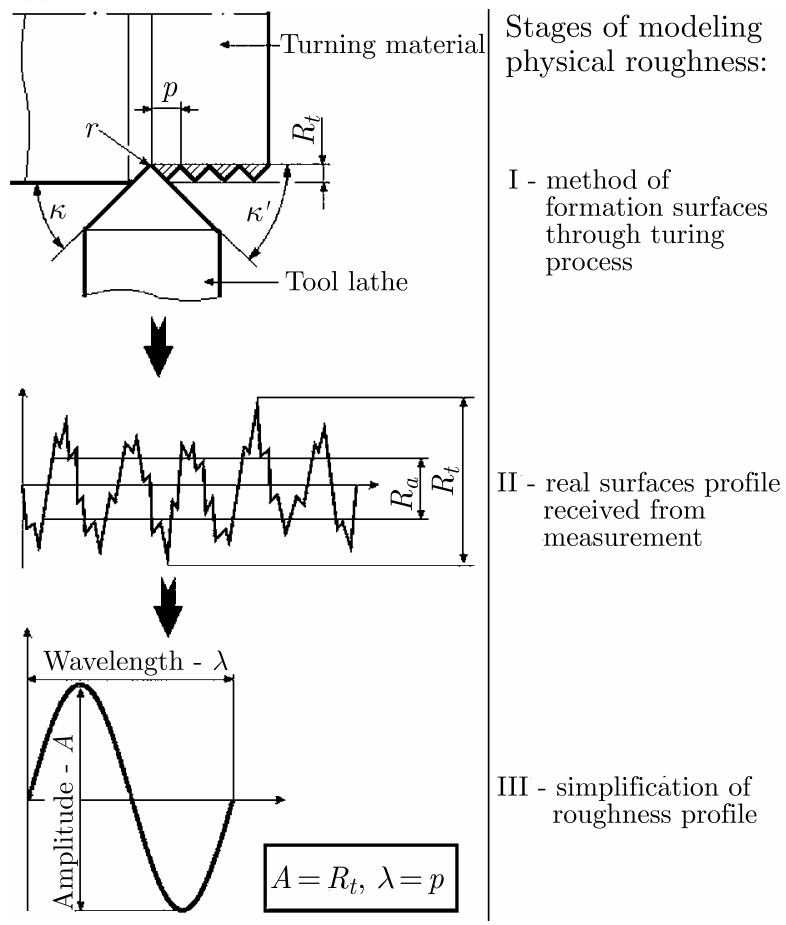

(b)

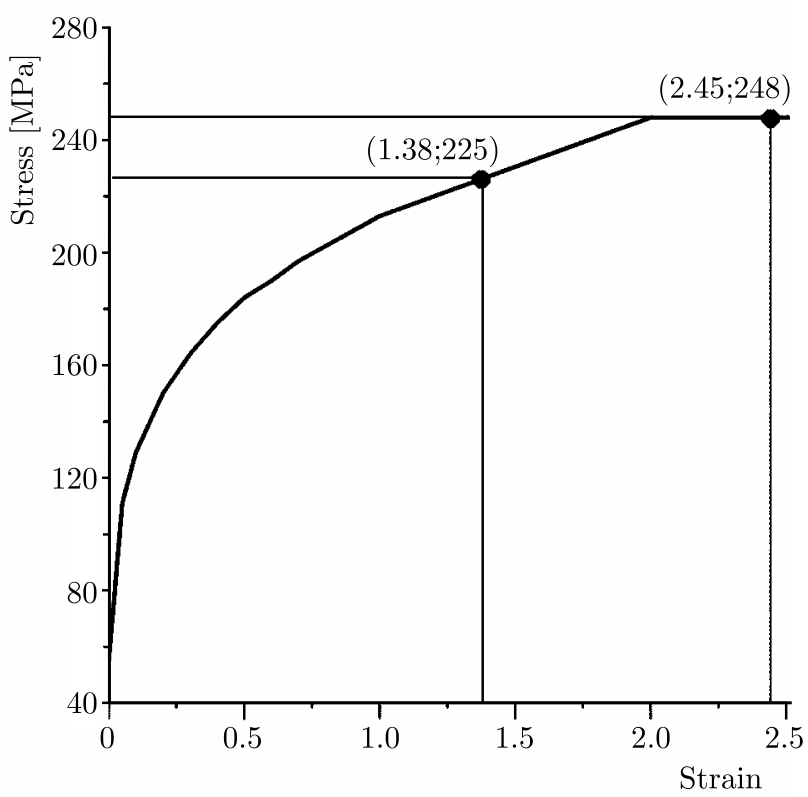

Fig. 1. (a) Stages of modeling physical roughness. (b) The stress-strain curve of aluminum alloy 6061-T0, the strain values in the deformation environment are multiplied ten times

Equation $(2.5)_{1}$ describes the dependency between the lathe feed during the turning process and the maximum height of the roughness profile, whereas equation $(2.5)_{2}$ is a well-known fundamental law describing the dependence between the feed rate, the radius of the corner and the arithmetic average values of the roughness profile

$$
R_{t}=p \frac{\tan \kappa \tan \kappa^{\prime}}{\tan \kappa+\tan \kappa^{\prime}} \quad R_{a}=\frac{p^{2}}{32 r}
$$

where: $R_{t}$ is the theoretical maximum roughness [mm], $R_{a}$ - arithmetic average values of the roughness profile, $p$ - feed $[\mathrm{mm} / \mathrm{rev}], \kappa$ - primary and secondary lead angle of the lathe $\left[^{\circ}\right]$, $r$ - radius of the corner.

Selecting turning parameters in the machining process, such as the feed, primary and secondary lathe angle as well as the value of radius of the corner, results in surface roughness having a sinusoidal character, which is a good method for representing work results (D'Addona and Raykarb, 2016). As was shown by Griffin et al. (2017), the real-time adjustment of other turning parameters such as rotation speed, tool pressure and tool wear (new tools in machining) or the use of acoustic emission signals allows a decrease in the distribution of height roughness. The use of acoustic emission signals in real-time control of parameters during the turning process produces surfaces without any defects such as waviness and height of roughness less than the parameter $R_{t}$. Griffin's work (Griffin et al., 2017) shows that proper steering of cutting parameters during the machining process results in $R_{t}$ parameter values nearly equal to $R_{a}$. Hence in our considerations of this issue, the roughness parameter $R_{t}$ is used instead of the parameter $R_{a}$. During the bonding process, small vertices of roughness disappear much faster than high ver- 
tices, and the calculation of two extreme positions of roughness (Fig. 2b) allows calculation of mean values of the height profile which will be the closest to that of the real roughness profile.

\section{Finite element analysis of the bonding process}

This paper presents a numerical study of the bonding process (Fig. 1a). Using the Finite Element Method (FEM), the authors have performed a numerical analysis of a model only within the plastic aspect of material deformation within the DEFORM environment. The numerical experiment was conducted on samples having dimensions of $\emptyset 1 \times 0.75 \mathrm{~mm}$ made of 6061 -T0 aluminum alloy on the assumption of specimen symmetry. The material stress-strain curve is presented in (Fig. 1b). The total displacement of the upper die used in the experiment was $1.37 \mathrm{~mm}$ with the direction of movement also being marked. The speed of the upper die during the bonding process was equal to $0.02 \mathrm{~mm} / \mathrm{s}$ while the starting temperature was $20^{\circ} \mathrm{C}$.

The plastic model is based on the HMH criterion as well as the isotropic material hardening model developed by Ottosen and Ritismanm (2005). The contact between the elements in FEM analysis is defined in the following manner: the dies are rigid (III and IV), samples show only plastic behavior (I and II) and the contact in pairs is assumed without the coefficient of friction. The discrete model of specimens has been made using 4500 quad elements for each sample.

(a)

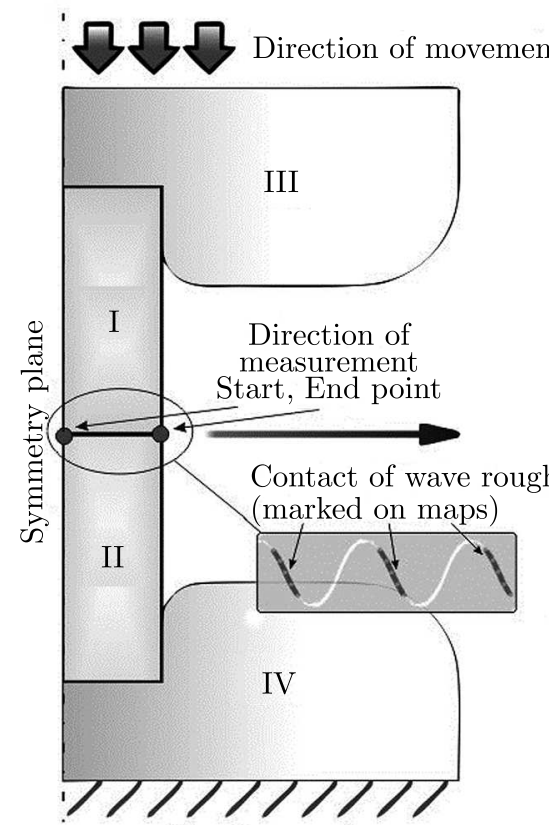

Fixed constrain

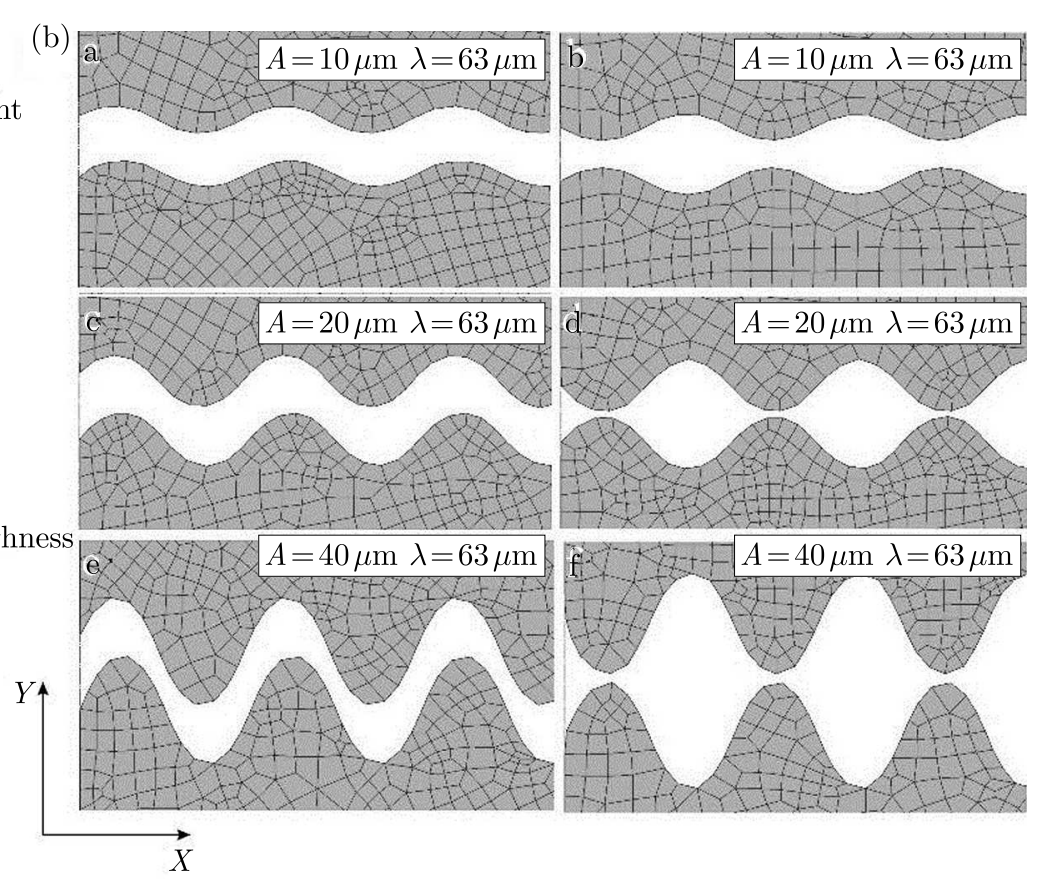

Fig. 2. (a) A diagram of the analysis of the bonding process. (b) Wave roughness profile: a, c, e wave in contact throughout the entire geometry ("wg" for short); b, d, f wave only in contact at its peak ("tow" for short)

The first wave (a, b) has an amplitude equal to10 $\mu \mathrm{m}$ and a length of $63 \mu \mathrm{m}$ (Fig. 2b), the second (c, d) has an amplitude of $20 \mu \mathrm{m}$ and a length of $63 \mu \mathrm{m}$ and the third wave (e, f) has an amplitude equal to $40 \mu \mathrm{m}$ and a length of $63 \mu \mathrm{m}$. Two variants of the same wave are also considered to examine the impact of wavy roughness on the assumption that $f=0$. In the case of $(\mathrm{b}, \mathrm{d}, \mathrm{f})$ only, the contact on the wave peak is considered while in (a, c, e), the contact is evaluated throughout the entire wave geometry. These two variants of wave positions allow a certain lack of perfect congruency of specimens relative to one other. Having the two extreme wave positions 
makes it possible to investigate the discrepancies in the results of any wave positions relative to one another and to calculate an average value. We should add that the roughness, microstructure as well as surface phenomena (adsorption etc.) play a significant role in welding technologies (including cold welding) which was confirmed in the work of Danwood et al. (2015). At the end of this Section we must stipulate however, that omission of the influence of the shear factor and creation of a friction model based only on micro-cutting does not adequately describe the entire frictional process. Such an approach to the modeling allows a quantitative description of the entire problem or differentiation between phenomena occurring during micro-cutting and the impact of the surface force in the frictional process. Further quantitative analysis of the friction process will allow a better understanding of the phenomena occurring in both friction and wear processes.

\section{Effective stress-strain distribution}

In attempting the analysis of effective plastic strain maps, it is necessary to identify fields of effective stress because their distributions are the same. After analyzing the charts of effective plastic strain (Fig. 3) it is clear that the material has a more homogeneous strain distribution for the "wg" contact than for the "tow" contact. Additionally, the "tow" contact displays a substantial strengthening of the material at vertices of wave roughness.
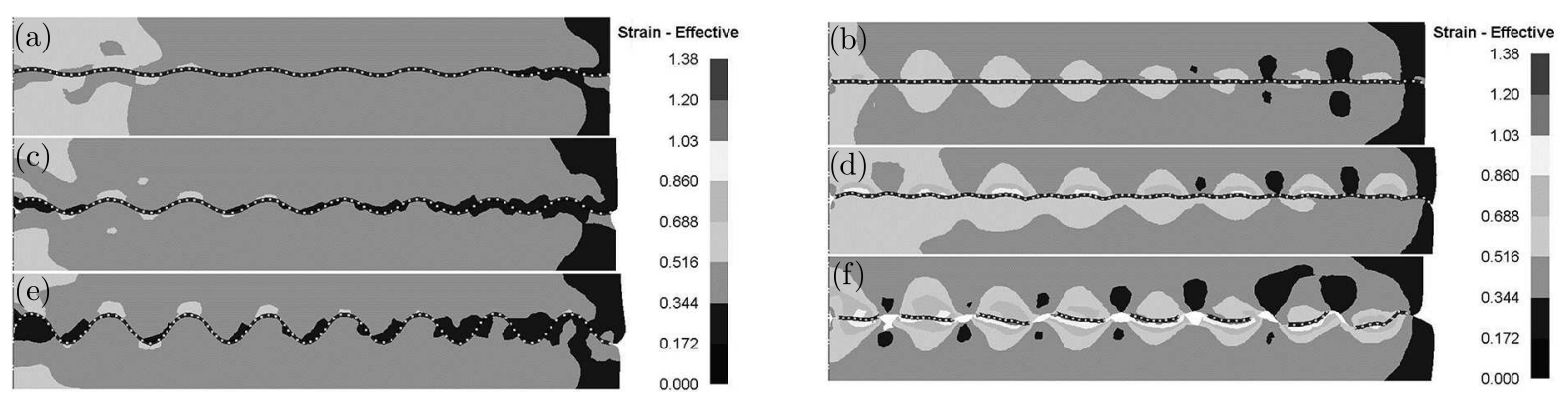

Fig. 3. Maps of the effective plastic strain for the upper die displacement equal to $0.5 \mathrm{~mm}$
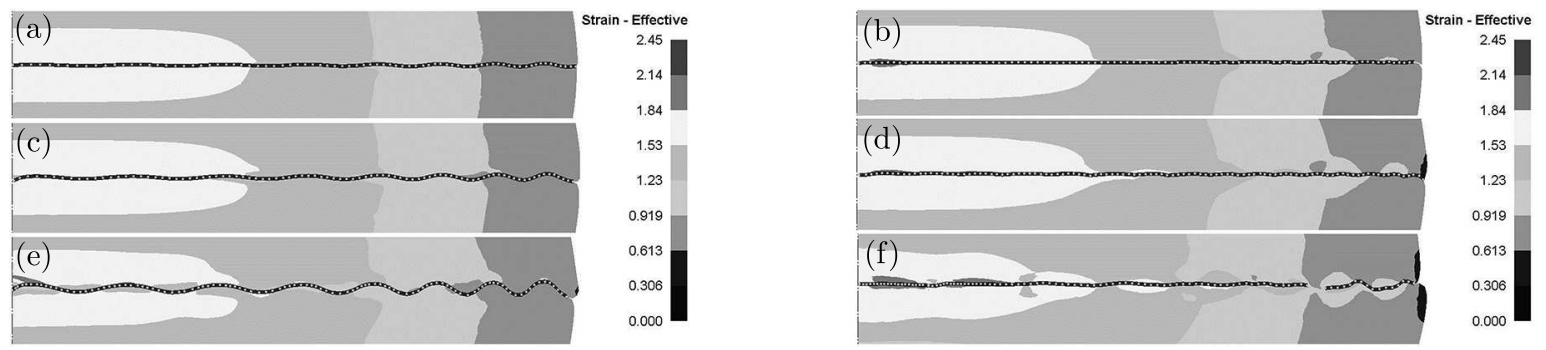

Fig. 4. Maps of the effective plastic strain for the upper die displacement equal to $1 \mathrm{~mm}$

During further movement of the upper die equal to $1 \mathrm{~mm}$, the effective plastic strain for each wave (Fig. 4) is homogeneously distributed. What is essential is that the whole process can be considered to be "cold" since the speed of the upper die, equal to $0.02 \mathrm{~mm} / \mathrm{s}$, caused a temperature increase by only about $5^{\circ} \mathrm{C}$. This small increase in temperature allows making an assumption that no phase transitions occur within the material. Based on the obtained stress and strain results, it is necessary to draw attention to the fact that the wave roughness has become flattened but has not been sheared off. This proves that the elements can not become bonded during the process because the oxidation of the surfaces is not eliminated through friction. Adjustment of bonding process parameters such as making the strain rate greater or 
the pressure higher does not create a plastic weld because contact surfaces are oxidized. The only proven way to make cold welding possible, described by Tang et al. (2009), is to previously purify the surfaces from contaminants and oxides and to conduct the entire process in a vacuum. In their experiment, they flattened copper-water micro heat pipe ends to achieve cold welds where plastic welds in a vacuum were obtained after the deformation of a copper tube at approximately one and a half of its yield strength. During their work, Tang et al. (2009) did not determine the criterion of cold welding but only determined an approximate starting point of the process of plastic welding on the compression force curve.

\section{Impact of micro-roughness}

Before we begin our discussion on the results obtained for contact surfaces, it is necessary to take another look at the diagram in Fig. 2a to ensure that the results of the analysis are being read correctly. In the zone of the plastic contact, it is possible to see the impact of the parameters of wave roughness. An increase in the amplitude of the wave causes a significant increase in the plastic strain in the area of contact (Fig. 5). A higher rise in strain is particularly observable in respect to the "tow" contact (Fig. 3). The growth of the strain during the bonding process is maintained despite the high deformation of the material. The upper die displacement equal to $1 \mathrm{~mm}$ (Fig. 5) causes a reduction in the obtained strain values between different waves. On the basis of this measurement, we can conclude that further deformation of the material does not cause plastic welding of contacting elements because most of the roughness vertices have already been flattened.

(a)

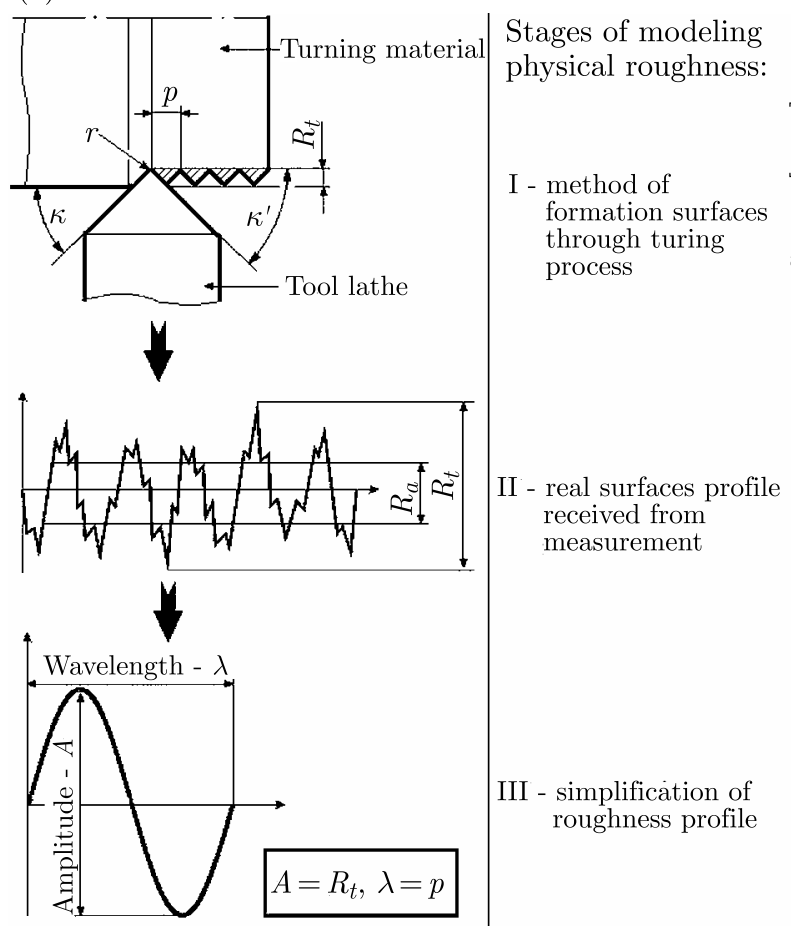

(b)

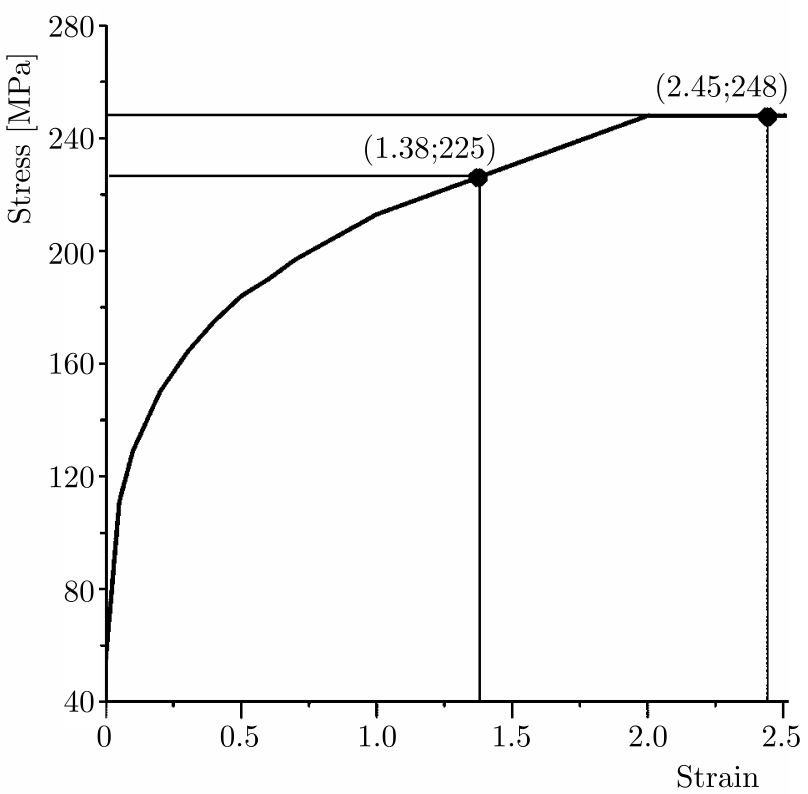

Fig. 5. Strain distribution for the upper die displacement equal to $0.5 \mathrm{~mm}$

When it comes to the micro-scale effect, Fig. 5 shows that a four-fold increase in the wave amplitude causes a 2-fold increase in the plastic strain for the "tow" contact. This effect varies (Fig. 6) and, at larger deformations, disappears much later for the "wg" contact than for the 
"tow" contact. Since this does not occur on the macro scale, it must be accredited to the micro-forming processes.
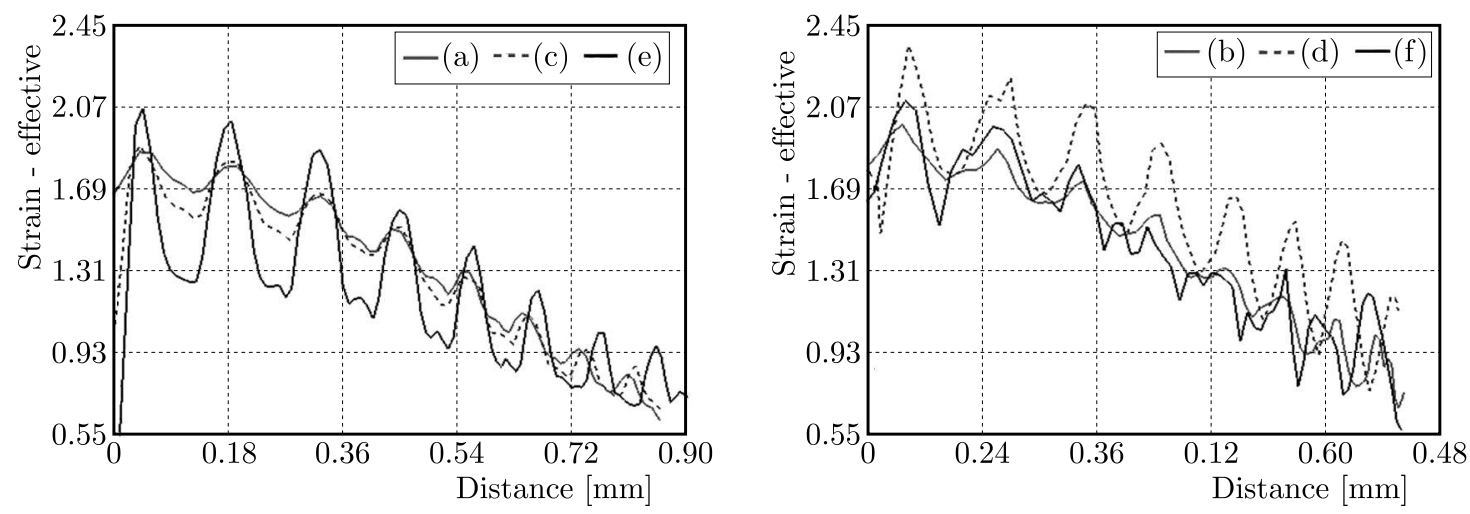

Fig. 6. Strain distribution for the upper die displacement equal to $\mathrm{mm}$

Table 1. Maximum, minimum and average strain values

\begin{tabular}{|c|c|c|c|c|c|c|c|c|}
\hline \multicolumn{7}{|c|}{ Average strain values } & Max & Min \\
\cline { 1 - 7 }$\left[\begin{array}{c}\text { Die displ. } \\
{[\mathrm{mm}]}\end{array}\right.$ & $\mathrm{a}$ & $\mathrm{c}$ & $\mathrm{e}$ & $\mathrm{b}$ & $\mathrm{d}$ & $\mathrm{f}$ & & \\
\hline \hline 0.5 & 0.4 & 0.49 & 0.39 & 0.37 & 0.56 & 0.69 & 1.21 & 0.2 \\
\hline 1 & 1.36 & 1.32 & 1.21 & 1.43 & 1.59 & 1.45 & 2.34 & 0.55 \\
\hline
\end{tabular}

During the analysis of the contact zone, it is also important to determine the average strain values since, on their basis, a specific relationship between the increase of plastic strain and the wave height can be established. Looking at Table 1, it is necessary to pay attention to the fact that a rise in wave height only causes an increase in the average strain value at the beginning of the bonding process (die displacement equal to $0.5 \mathrm{~mm}$ ). For "tow" contact surfaces an increase between wave $\mathrm{b}$ and wave $\mathrm{d}$ was equal to $0.19(33 \%)$ while between wave $\mathrm{b}$ and wave $\mathrm{f}$ it reached $0.32(46 \%)$, but no such a dependency was observed for the "wg" contact. Further deformation (die displacement equal to $1 \mathrm{~mm}$ ) for "wg" contact resultef in a decrease of the average strain value between wave a and wave c equal to $0.04(2.9 \%)$ and between wave a and wave e equal to $0.15(11 \%)$ while no such dependency was observed for the "tow" contact.

An analysis of the maximum shear stress on contact surfaces shows that vertices of micro-roughness are compressed rather than sheared, a fact which is confirmed by data in graphs of the effective plastic strain and shear stress. The authors emphasize this fact because it is essential to the performed analysis. A greater share of shear stress, no less than $57 \%$, than that of the normal stress in the effective stress is a prerequisite for obtaining plastic welds.

Looking at Fig. 7, it is possible to observe that the impact of micro-roughness on the distribution of shear stress is much less than that on of the effective plastic strain. The differences between different waves and positions of fields are small. Displacement of the upper die equal to $1 \mathrm{~mm}$ (Fig. 8) shows that the distribution of shear stress is much more uneven than that of the effective plastic strain. Disturbances occurring only at the ends of measurement fields have no significant impact on the bonding process.

The dependence between wave height and high deformation of specimens in the bonding process cannot be seen by studying the received average values of shear stress presented in Table 2. An analysis of the obtained average shear stress values shows a diminishing difference between any wave and its positions as the sample deformation increases. Additionally, a study of the average shear stress values proves that their share in the effective stress is less than $52 \%$, making creation of a plastic weld impossible. 

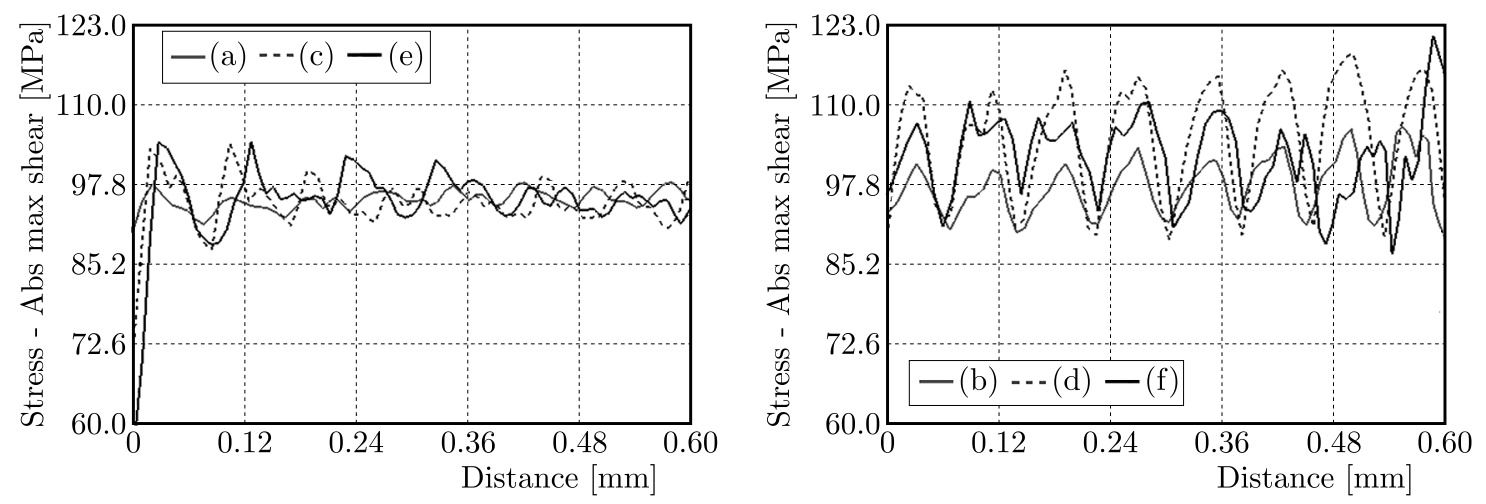

Fig. 7. Shear stress distribution for the upper die displacement equal to $0.5 \mathrm{~mm}$
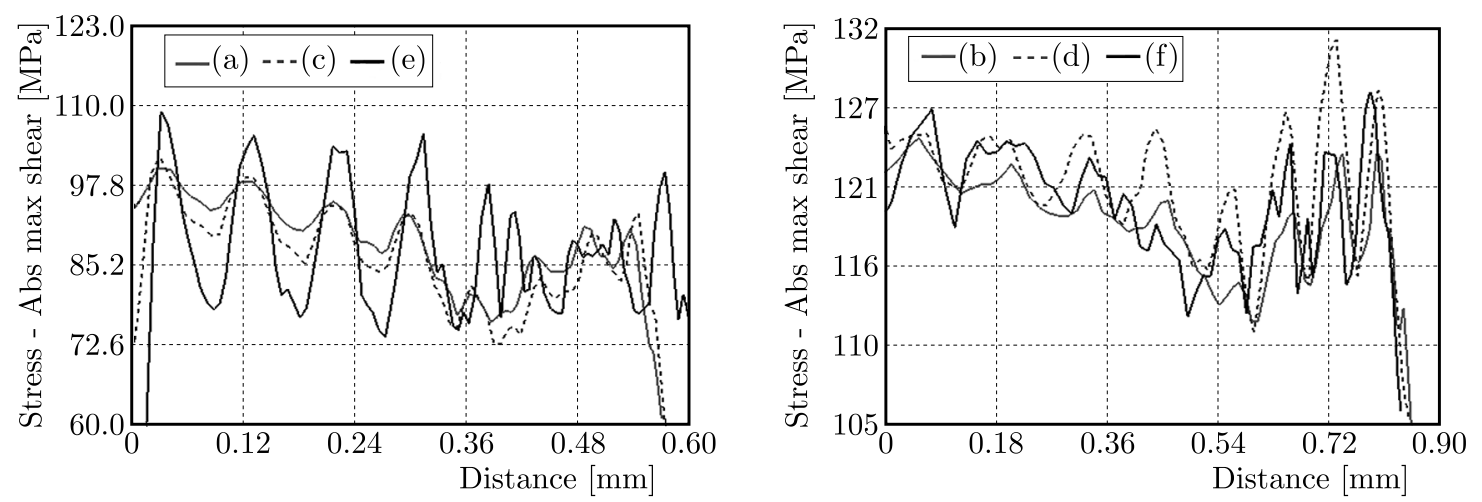

Fig. 8. Shear stress distribution for the upper die displacement equal to $1 \mathrm{~mm}$

Table 2. Maximum, minimum and average stress values

\begin{tabular}{|c|c|c|c|c|c|c|c|c|}
\hline \multicolumn{7}{|c|}{ Average strain values } & Max & Min \\
\cline { 1 - 1 } $\begin{array}{c}\text { Die displ. } \\
{[\mathrm{mm}]}\end{array}$ & $\mathrm{a}$ & $\mathrm{c}$ & $\mathrm{e}$ & $\mathrm{b}$ & $\mathrm{d}$ & $\mathrm{f}$ & & \\
\hline \hline 0.5 & 93 & 94 & 84 & 97 & 105 & 102 & 121 & 60 \\
\hline 1 & 117 & 116 & 116 & 119 & 121 & 120 & 131 & 105 \\
\hline
\end{tabular}

The results of strain rate distribution in the initial stage of specimen deformation (upper die displacement equal to $0.5 \mathrm{~mm}$ ) along with the data presented in Fig. 9 show a substantial influence of the wave amplitude. The impact of the parameters of wave roughness decreases with an increase in sample deformation. Figure 10 shows that the importance of wave parameters remained significant only for wave e. Further deformation causes the influence of wave roughness on the strain rate distribution to disappear all together. The last two graphs of the strain rate distribution indicate a significant growth in the deformation speed and a homogeneous distribution of these values on both contacting surfaces. This fact suggests that the point where there is an increase in the rate of high strain determines weld formation, something that has been proven in the work of Piwnik et al. (2011, 2014). In this case, the anastomosis of both contact surfaces does not occur because flattened vertices of roughness are too highly oxidized.

An analysis of Table 3 shows that the values of average strain rate decrease as sample deformation increases for any contact ("wg" and "tow"). The first step of deformation (upper die displacement equal to $0.5 \mathrm{~mm}$ ) shows a decrease in the average strain rate between waves $\mathrm{a}$ and $\mathrm{c}$ equal to 0.001 (4.3\%), between a and e equal to 0.003 (13\%), between $\mathrm{b}$ and $\mathrm{d}$ equal to $0.002(8.3 \%)$, and between $\mathrm{b}$ and $\mathrm{f}$ equal to $0.004(16 \%)$. Further deformation (upper die displacement equal to $1 \mathrm{~mm}$ ) results in a decrease of the average strain rate between waves a 

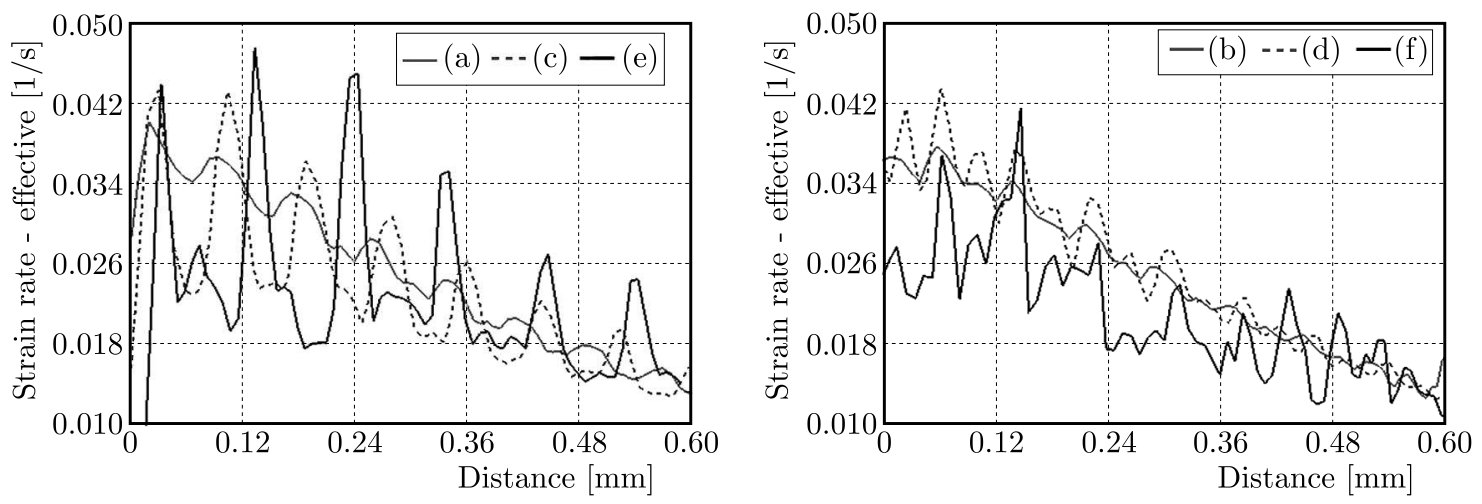

Fig. 9. Strain rate distribution for the upper die displacement equal to $0.5 \mathrm{~mm}$
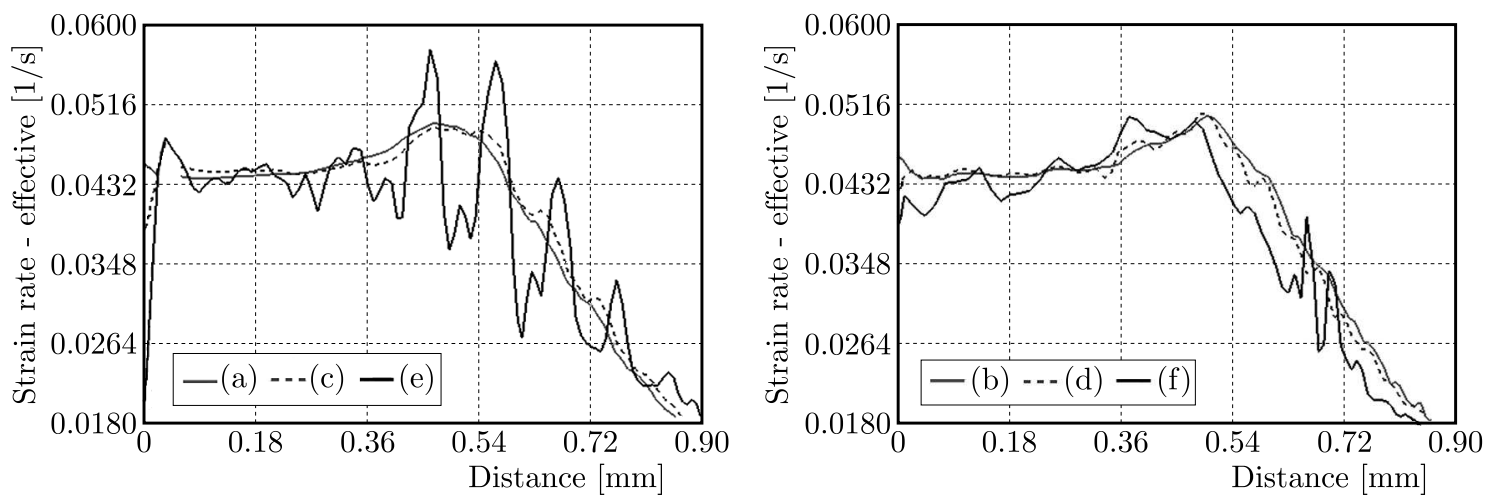

Fig. 10. Strain rate distribution for the upper die displacement equal to $1 \mathrm{~mm}$

Table 3. Maximum, minimum and average stress values

\begin{tabular}{|c|c|c|c|c|c|c|c|c|}
\hline \multicolumn{7}{|c|}{ Average strain values } & Max & Min \\
\cline { 1 - 6 }$\left[\begin{array}{c}\text { Die displ. } \\
{[\mathrm{mm}]}\end{array}\right.$ & $\mathrm{a}$ & $\mathrm{c}$ & $\mathrm{e}$ & $\mathrm{b}$ & $\mathrm{d}$ & $\mathrm{f}$ & $\mathrm{n}$ & \\
\hline \hline 0.5 & 0.023 & 0.022 & 0.02 & 0.024 & 0.022 & 0.02 & 0.046 & 0.01 \\
\hline 1 & 0.041 & 0.041 & 0.038 & 0.041 & 0.04 & 0.039 & 0.055 & 0.018 \\
\hline
\end{tabular}

and $\mathrm{c}$ of less than $1 \%$, between a and e equal to $0.003(7.3 \%)$, between $\mathrm{b}$ and $\mathrm{d}$ equal to 0.001 $(2.4 \%)$, and between $\mathrm{b}$ and $\mathrm{f}$ equal to $0.002(4.8 \%)$.

\section{Strain work of "grains"}

When analyzing the presented issue, we should also consider the aspects of grain micro-mechanics. Based on the work of Ortiz et al. (2007), the average grain size of aluminum alloy 6061 is approximately $30 \mu \mathrm{m}$ long and about $13 \mu \mathrm{m}$ wide. These values are an average, and their approximation is intended to indicate the number of grains in one vertex of roughness. Based on these estimates, we can establish that one grain accrues for wave $a, b$, two grains accrue for wave $\mathrm{c}, \mathrm{d}$, and three grains accrue for wave e, f. The surface roughness resulting from the turning process changes the properties of these grains and, grains near the surface will display varying values of yield strength. Insignificant differences between the yield strength of single grains of the contact surfaces can affect the cold welding process because the fast local growth of the coefficient of friction on the two different, newly created surfaces of a medium, can cause formation of local welds. A different strain rate of both surfaces causes an increase in 
the coefficient of friction. A prerequisite for this increase is a more significant share of the shear stress in the effective plastic stress. Tiny pieces of this material, $1 \mu \mathrm{m} \times 1 \mu \mathrm{m}$ in size, have been isolated and the strain calculated (6.1) along the trajectory of plastic flow (Fig. 11.)

$$
W=\iint_{A} \sigma \dot{\varepsilon} d A \quad W_{\tau}=\iint_{A} \sigma_{\tau} \dot{\varepsilon} d A
$$

where: $W$ is the strain work $[\mathrm{J}], W_{\tau}$ - strain work of shear $[\mathrm{J}], \dot{\varepsilon}$ - effective strain rate $[1 / \mathrm{s}]$, $A$ - grain surface area $\left[\mu \mathrm{m}^{2}\right], \sigma$ - effective plastic stress $[\mathrm{MPa}], \sigma_{\tau}$ - abs. max shear $[\mathrm{MPa}]$.

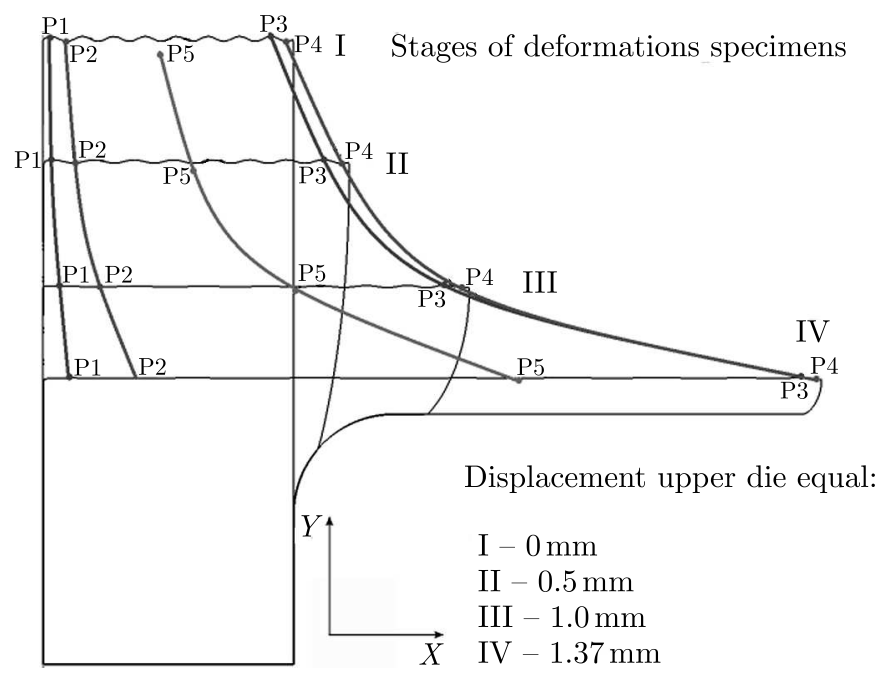

Fig. 11. Trajectory of the material plastic flow

(a)

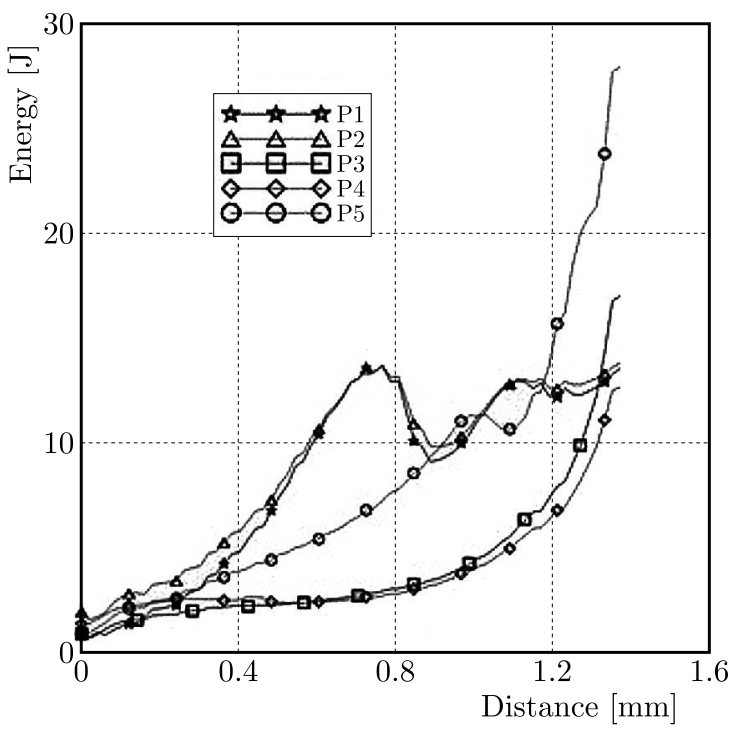

(b)

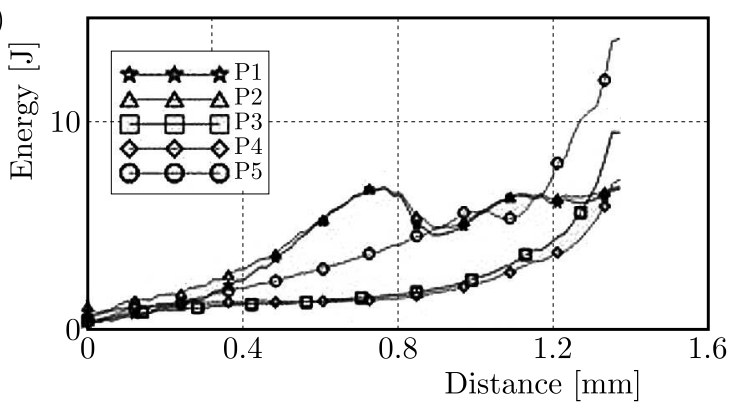

Fig. 12. (a) Effective strain rate. (b) Strain rate of shearing

The results of deformation studies show that the effective strain under stress (Fig. 12a) is much higher than shear stress (Fig. 12b). These results also suggest that further deformation of specimens will not result in a plastic weld because the share of shear stress in the effective plastic stress is too small, and the oxidation of the surfaces cannot be removed through friction. In analysis of the obtained graphs presenting the deforming forces, it is also possible to see that the increase of the plastic flow intensity results in considerable energy demand for carrying out 
the bonding process. At points $P 1$ and $P 2$, a significant energy demand occurs much earlier than at other points and increases for the upper die displacement equal to $0.76 \mathrm{~mm}(13.6 \mathrm{~J}, 6.8 \mathrm{~J})$ then slowly decreases and increases gradually for the upper die displacement of $0.9 \mathrm{~mm}(9.5 \mathrm{~J}, 4.7 \mathrm{~J})$. A slow exponential growth for the energy demand can be seen in points $P 3$ and $P 4$. Point $P 5$ seems to be the most interesting because at the beginning of the bonding process it shows an almost linear increase of the energy demand at $0.92 \mathrm{~mm}(10 \mathrm{~J}, 5.1 \mathrm{~J})$ with a sinusoidal energy demand at $1.1 \mathrm{~mm}(10.8 \mathrm{~J}, 5.5 \mathrm{~J})$ and then a rapid exponential growth at $1.37 \mathrm{~mm}(29 \mathrm{~J}, 14.5 \mathrm{~J})$. At any set of points the share of shear strain is less than $57 \%$ in relation to the effective strain which makes it impossible to obtain a plastic weld. If the test surfaces are free of contaminates and are not oxidized then the first plastic welds would occur at point $P 5$. The choice of points at which energy is measured is random, and the real starting point of weld formation must be determined in an experimental study. Although this would not allow creation of a plastic weld it would at least confirm the presented hypothesis that cold welding of materials is possible under large plastic deformation during the bonding process as proven in the previously mentioned works (Tang et al., 2009) where plastic welds were achieved with flattened copper-water micro heat pipe ends in vacuum after deformation of approximately one and a half of the yield strength.

\section{Conclusions}

Analysis of the bonding process between two perfectly plastic bodies revealed the influence of roughness at the micro-scale and enabled formulation of a hypothesis that metal alloys can be cold welded. The following have been observed in micro-scale: tremendous impact of the wave amplitude on the obtained values of plastic strain in the initial stages of deformation, growth equal to $33 \%$ for 2 -fold wave amplitude and $46 \%$ for 4 -fold wave amplitude. The wave amplitude as well as its relative position to other waves impact its rate of decay and, with increasing deformation of specimens, on the obtained values of strain, strain rate and stress. A decrease in strain rate values has also been observed with the increasing wave amplitude within the range from $2.4 \%$ to $16 \%$. Based on the map of the strain and stress distribution as the specimen deformation increases, it can be concluded that an increase in the wavelength has a lesser impact on the obtained values and on the rate of decay of wave roughness. Analysis of the bonding process from the perspective of cold welding revealed that an insufficient share of shear stress, less than $57 \%$, relative to effective plastic stress makes it impossible to remove the oxidized layer of the material, which prevents the surfaces from bonding. An increase in the wave roughness and grain size effect promotes the effectiveness of the cold welding process. The strain along the trajectory of the material plastic flow is probably the site of plastic weld formation.

\section{References}

1. Abdo J., Farhgang K., 2005, Elastic-plastic contact model for rough surfaces based on plastic asperity concept, International Journal of Non-Linear Mechanics, 40, 4, 495-506

2. Brzoza A., Pauk V., 2007, Axially symmetric contact involving friction and boundary roughness, Journal of Theoretical and Applied Mechanics, 45, 2, 277-288

3. Buczkowski R., Kleiber M., 1992, Finite element analysis of elastic-plastic plane contact problem with nonlinear interface compliance, Journal of Theoretical and Applied Mechanics, 4, 30.

4. Cai S., Bhusman B., 2005, A numerical three-dimensional contact model for rough, multilayered elastic/plastic solid surfaces, Wear, 259, 7-12, 1408-1423

5. D'Addona D.M., RaYkarb S.J., 2016, Analysis of surface roughness in hard turning using wiper insert geometry, Procedia CIRP, 41, 841-846 
6. Danwood H.I., Mohammed K.S., Rahmat A., Uday M.B., 2015, The influence of the surface roughness on the microstructures and mechanical properties of 6061 aluminum alloy using friction stirwelding, Surface and Coatings Technology, 270, 272-283

7. Griffin J.M., Diaz F., Geerling E., Clasing M., Ponce V., Taylor C., Tuner S., Michael E.A., Mena F.P., Bronfman L., 2017, Control of deviations and prediction of surface roughness from micro machining of $\mathrm{THz}$ waveguides using acoustic emission signals, Mechanical Systems and Signal Processing, 85, 1020-1034

8. Ma X., Rooij M., Schipper D., 2010, A load dependent friction model for fully plastic contact conditions, Wear, 269, 11-12, 28, 790-796

9. Manoylov A.V., Bryant M.J., Evans H.P., 2013, Dry elasto-plastic contact of nominally flat surfaces, Tribology International, 65, 248-258

10. Matsumoto R., Hayashi K., Utsunomiya H., 2014, Experimental and numerical analysis of friction in high aspect ratio combined forward-backward extrusion with retreat and advance pulse ram motion on a servo press, Journal of Materials Processing Technology, 214, 936-944

11. Ortiz D., Abdelsheid M., Dalton R., Soltero J., Clark R., 2007, Effect of cold work on the tensile properties of 6061, 2024, and $7075 \mathrm{Al}$ alloys, Journal of Materials Engineering and Performance, 16, 5, 515-520

12. Ottosen N.S., Ritismanm., 2005, The Mechanics of Constitutive Modeling, Lund University, Sweden

13. Piwnik J., Mogielnicki K., 2010, The friction influence on stress in micro extrusion, Archives of Foundry Engineering, 10, Special Issue 1/2010, 451-454

14. Piwnik J., Kuprianowicz J., Mogielnicki K., 2011, Numerical modeling of the welding phenomenon in forward aluminum extrusion process, Archives of Foundry Engineering, 11, Special Issue 2/2011, 191-194

15. Piwnik J., Mogielnicki K., Kuprianowicz J., 2014, Numerical analysis of friction influence on the transverse welding phenomenon in the forward extrusion process, Journal of Theoretical and Applied Mechanics, 52, 2, 547-555

16. Poulios S., Klit P., 2013, Implementation and applications of a finite-element model for the contact between rough surfaces, Wear, 303, 1-2, 15, 1-8

17. Sun F., Giessen E.V., Nicola L., 2012, Plastic flattening of a sinusoidal metal surface: A discrete dislocation plasticity study, Wear, 296, 672-680

18. TAn X., 2002, Comparison of friction models in bulk metal forming, Tribology International, 35 , 385-393

19. TAng Y., Lu L., Deng D., YuAn D., 2009, Cold welding sealing of copper-water micro heat pipe ends, Transactions of Nonferrous Metals Society of China, 19, 568-574

20. Wang L.G., Sun X.P., Huang Y., 2007, Friction analysis of microcosmic elastic-plastic contact for extrusion forming, Journal of Materials Processing Technology, 187-188, 631-634

21. Zhang S., Hodgson P.D., Cardew-Hall M.J., Kalyanasundaram S., 2003, A finite simulation of micro-mechanical frictional behavior in metal forming, Journal of Materials Processing Technology, 134, 81-91

22. Zhang S., Wang W., Zhao Z., 2014, The effect of surface roughness characteristic on the elastic-plastic contact performance, Tribology International, 79, 59-73 